\title{
Mechanical and hydrodynamic swelling characteristics of bovine tanned leather post-treated by acrylic and glutaraldehyde tanning agents
}

\author{
A. Mondal and P. K. Chattopadhyay* \\ Government College of Engineering and Leather Technology, Salt Lake, Kolkata - 700098, India
}

\begin{abstract}
Chromium tanned cow hides collected at two different stages (i.e. pre-neutralization and pre-finishing) have been treated separately with acrylic and glutaraldehyde based tanning agents. Both mechanical and hydrodynamic swelling properties of these treated samples were investigated. Observed results revealed that overall tensile properties and resistance against hydrodynamic swelling have been improved in all the treated samples as compared to those of untreated samples. Such improvement has been realized through measurement of crosslink densities via fitment of Mooney-Rivlin equation on the tensile plot. Leather post-treated with acrylic copolymer has envisaged superior results as compared to leather post-treated with gluteraldehyde based tanning agent. After one swelling / deswelling cycle, slight material loss has been incurred in all the samples, which is the highest for leather post-treated with glutaraldehyde. Such post-treatment of leather can be a useful measure to enhance the performance properties of leather samples already manufactured in the tannery.
\end{abstract}

Keywords: Crosslink density; Mooney-Rivlin equation; Swelling kinetics; Deswelling

\section{Introduction}

Leather is a durable and flexible material obtained by tanning of animal raw hide and skin $(\mathrm{h} / \mathrm{s})$, and leather processing involves a number of unit processes and operations (Thanikaivelan et al., 2002). Basically, tanning is a unit process of converting putrescible outer covering of animals to non-putrescible leathers with definite physical, chemical, and biological properties (Dutta, 1985). In fact, tanning is a treatment of a natural fibre protein (i.e. collagen) from hides and skins, which leads to stabilization of the material. This stabilization is mainly an increase in resistance against hydrolysis which restricts swelling. This property change is mainly ascribed to the cross-linking of tanning material with collagen, filling effect of tanning material and is also promoted by hydrophobic coating of collagen fibre (e.g. fatliquoring) etc. In fact, an effective tanning agent potentially increases the number of new type of stable cross-linkages among the poly peptide chains. In addition, for transformation of collagen to leather, reactivity of collagen is also crucial, which is mainly decided by the content of acidic and basic amino acids, amino acids containing - $\mathrm{OH}$ groups and peptide groups (Heidemann, 1993). Therefore, a potential tanning agent should possess the ability to generate crosslinks which should be stable at a temperature that is at least higher than the denaturation temperature of untanned collagen. Moreover, resistance to hydrodynamic swelling and tensile modulus are directly related to the crosslinking density of leather which is generally dependent upon the performance of the tanning agents inside $\mathrm{h} / \mathrm{s}$ matrix (Heidemann, 1993).

Acrylic type tanning agents or polyacrylates are synthesized mainly through addition polymerization. These tanning agents contain many carboxylic acid side groups that can give tanning property both reacting with multiple chrome centers on the leather and chemical binding to the collagen groups (Jankauskaité et al., 2012). Basically, polyacrylate type tanning agents are polyacrylic acids copolymerized with a portion of methacrylate or maleinate etc. Furthermore, a certain number of acrylic acid groups are esterified. Generally, the particular group of tanning agents should be of low molecular weight to ensure easy penetration inside $\mathrm{h} / \mathrm{s}$ matrix (Heidemann, 1993).

Glutaraldehyde is a 5-carbon dialdehyde with a linear structure and is mainly available in acidic aqueous solutions $(\mathrm{pH}$ $3.0-4.0$ ), in concentration ranging from less than $2 \%$ to $70 \%$ (w/v) (Migneault, 2004). Glutaraldehyde can react with various functional groups of protein, amine, thiol, phenol, and imidazole. Moreover, glutaraldehyde exists in multiple forms in aqueous solution. All of these forms might be reactive towards lysine residues of collagen bearing $\varepsilon$-amino group. All reported forms of glutaraldehyde have the ability to react and crosslink proteins (Tyagi et al., 2014).

\footnotetext{
*Corresponding author. e-mail: pkantichattopadhyay@gmail.com
} 
The suitability of polyacrylic or poly methacrylic acid for use as a tanning agent, particularly in chrome tanning, is already established (Christner et al., 1990). Variation of glass transition temperatures in the leathers being tanned with different tanning agents were compared by Jeyapalina et al. (Jeyapalina et al., 2007). Recently a new synthetic tanning agent has been developed which is able to replace commercial urea formaldehyde resin in leather retanning process due to better retanning performance (Saleem et al., 2013). Tyagi et al. reported the considerable improvement in thermal, mechanical and swelling resistance properties for bovine samples treated with $3 \%$ GT-50 $(\mathrm{w} / \mathrm{w})$ (Tyagi et al., 2014). Crosslinking and tensile strength in collagen based biomaterials (obtained by purifying dermal sheep collagen) was reported to be enhanced by treating with glutaraldehyde (Damink et al., 1995).

In this work, the main objective is to improve the mechanical properties and resistance towards hydrodynamic swelling of the crusts already manufactured in tannery. These properties of the crusts may be improved by post-treatment with suitable tanning agent (i.e. aqueous solutions of gluteraldehyde and acrylic tanning agents). Contribution of different factors like region of hides (e.g. butt, neck), tanning agents (e.g. aldehyde, acrylic), and processing stages would be investigated regarding improvement in mechanical and hydrodynamic swelling properties.

\section{Materials and methods}

\section{Materials}

Raw materials like cow wet blues (shaved thickness $=1.1$ $1.3 \mathrm{~mm}$, weight $=6 \mathrm{Kg}$ ) were supplied by Viswaat Chemicals Ltd., India. Leather auxiliaries like detergents, dyes, lubricating agents, tanning/ retanning agents, fixing agents etc. were provided by Viswaat Chemicals Ltd., India. Acrylic synthetic tanning agent like Relugan RE and glutardehyde tanning agent like Relugan GT-50 were provided by BASF India Limited.

\section{Sample preparation}

Both rechromed and crust leather samples were prepared following the generalized unit operations for leather manufacturing based on the recipes (Table I and Table II). Thereafter, prepared samples were further treated separately with Relugan RE and Relugan GT-50, and the solid contents of the end baths produced during RE \& GT-50 treatment were evaluated (Table III).

\section{Characterization}

\section{Mechanical properties}

The mechanical behavior including the crosslinking density of the samples was investigated by the tensile test. Initially, both the samples were conditioned at $25^{\circ} \mathrm{C}$ and $65 \pm 2 \%$ R.H for 48 hours. The usual dog bone shaped specimens were punched out from the crusts with ASTM Die-C. The measurement as per ASTM D-2209-00 standard was carried out in a Hicks-Hounsfield UTM-H10 KS (Test Equipment, Surrey, England) maintaining a cross head speed of $254 \pm 50$ $\mathrm{mm} . \mathrm{min}^{-1}$ at $25^{\circ} \mathrm{C}$. The averages of five tests were reported for each sample. The stress-strain curve was plotted with Lab Tensile software, from which the tensile modulus, tensile strength and elongation-at-break (EB) were calculated. In each case, the error corresponding to tensile modulus, tensile strength, EB measurement was limited to $\pm 1 \%, \pm 2 \%, \pm 2$ $\%$, respectively.

Crosslink densities of samples were measured based on the Mooney-Rivlin equation (equation 1) which is suitable to measure the degree of crosslink of samples by fitting the data obtained from stress strain results (Tyagi et al., 2014).

$$
\frac{\sigma_{a v}}{2\left(\lambda-\lambda^{-2}\right)}=C_{1}+\frac{C_{2}}{\lambda}
$$

where, $C_{1}$ and $C_{2}$ are constants. The values of $C_{1}$ and $C_{2}$ can be determined by fitting the plot of $\frac{\sigma_{a v}}{2\left(\lambda-\lambda^{-2}\right)}$ against $\frac{1}{\lambda}$ in the Mooney-Rivlin equation. The value of $C_{l}$ can be used to determine crosslink density by the following equation:

$N_{C}=\frac{2 C_{1}}{R T}$

where, $N_{C}$ is the crosslink density, $R$ is the gas constant $\left(8.314 \mathrm{~J} . \mathrm{deg}^{-1} \cdot \mathrm{mol}^{-1}\right)$ and $T$ is the absolute temperature.

\section{Swelling}

Circular test specimens of diameter $22 \mathrm{~mm}$ (approx.) were cut out from all the leather samples. Thicknesses of the circular samples were measured using a thickness measuring gauge (Type JO2), manufactured by S. C. Dey \& Co., having range of $0.01-10 \mathrm{~mm}$. At least 5 sets of the circular specimens of all the samples, i.e. untreated, Relugan RE treated, Relugan GT-50 treated samples, were weighed accurately by an electronic balance. Subsequently, they were allowed to 
Table I. Recipes for the preparation of all the rechromed samples ${ }^{a}$

\begin{tabular}{|c|c|c|c|c|c|}
\hline \multirow[b]{2}{*}{ Process } & \multirow[b]{2}{*}{ Ingredients } & \multicolumn{3}{|c|}{ Samples (ingredients in \%) } & \multirow[b]{2}{*}{$\begin{array}{c}\text { Running } \\
\text { time }\end{array}$} \\
\hline & & $\begin{array}{l}\mathrm{BRA}_{0} \mathrm{G}_{0} / \\
\mathrm{NRA}_{0} \mathrm{G}_{0}\end{array}$ & $\begin{array}{l}\mathrm{BRA}_{10} \mathrm{G}_{0} / \\
\mathrm{NRA}_{10} \mathrm{G}_{0}\end{array}$ & $\begin{array}{l}\mathrm{BRA}_{0} \mathrm{G}_{10} / \\
\mathrm{NRA}_{0} \mathrm{G}_{10}\end{array}$ & \\
\hline \multirow[t]{3}{*}{ Soak back } & Water & 200 & 200 & 200 & \\
\hline & Non-ionic detergent & 0.5 & 0.5 & 0.5 & \\
\hline & Oxalic acid & 1 & 1 & 1 & $30^{\prime}$ \\
\hline \multirow[t]{12}{*}{ Rechroming } & Water & 100 & 100 & 100 & \\
\hline & Acid Black dye & 1 & 1 & 1 & $10^{\prime}$ \\
\hline & Formic acid & 1 & 1 & 1 & $20^{\prime}$ \\
\hline & Glutaraldehyde & 3 & 3 & 3 & $20^{\prime}$ \\
\hline & Basic chromium sulfate & 4 & 4 & 4 & \\
\hline & Chrome syntan & 3 & 3 & 3 & \\
\hline & Non-ionic detergent & 0.1 & 0.1 & 0.1 & $30^{\prime}$ \\
\hline & Sulphited fish oil & 1 & 1 & 1 & $15^{\prime}$ \\
\hline & Phenolic syntan & 1 & 1 & 1 & \\
\hline & Melamine syntan & 1 & 1 & 1 & $20^{\prime}$ \\
\hline & Sodium formate & 1 & 1 & 1 & $10^{\prime}$ \\
\hline & Polymeric syntan & 3 & 3 & 3 & $2 \times 10^{\prime}+30^{\prime}$ \\
\hline \multirow[t]{3}{*}{ Syntan treatment } & Water & - & 200 & 200 & \\
\hline & Relugan RE & - & 10 & - & $60^{\prime}$ \\
\hline & Relugan GT-50 & - & - & 10 & $60^{\prime}$ \\
\hline
\end{tabular}

a = Following designations have been followed:

$\mathrm{B}=$ Butt portion of leather; $\mathrm{N}=$ Neck portion of leather; $\mathrm{R}=$ Rechromed leather; $\mathrm{A}=$ Acrylic syntan (Relugan RE); $\mathrm{G}=$ Glutaraldehyde syntan (Relugan GT-50); Subscript of $A=\%$ of Acrylic syntan (Relugan RE); Subscript of $G=\%$ of Glutaraldehyde syntan (Relugan GT-50).

swell in distilled water at $25^{\circ} \mathrm{C}$ for $72 \mathrm{~h}$ to ensure attainment of equilibrium swelling state. Thereafter, as the swelled samples reached the equilibrium state, were allowed to deswell for further $72 \mathrm{~h}$ in open air.

In each case, during swelling and deswelling, weights of samples were measured at specified time (i.e. at $30 \mathrm{~min}, 60$ min, $120 \mathrm{~min}, 240 \mathrm{~min}, 360 \mathrm{~min}, 1440 \mathrm{~min}, 2880 \mathrm{~min}$, and $4320 \mathrm{~min}$ or $72 \mathrm{~h}$ ). The weight measurements of the samples undergoing swelling at specified point of time were executed after careful removal of the fluid adhered at the surface of the specimens with the help of blotting paper. Thereafter, at the end of swelling, solid contents of the baths have been determined for each sample (Table III). Finally, all the swelling data were analyzed based on the following parameters:

\section{Calculation of the mol \% uptake of the distilled water}

Mol \% uptake of water during swelling for the leather samples can be measured by the following equation (Mathew et al., 2006):
$Q_{t}=\frac{W_{f}-W_{0}}{M_{S} \cdot W_{0}} \times 100$

where, $Q_{t}$ is the mol \% uptake of water. $W_{f}$ and $W_{o}$ are weights of the leather samples before and after the swelling and $M_{S}$ is the molar mass of water.

\section{Swelling coefficient}

The swelling coefficient $(\alpha)$ helps to analyze the swelling behavior of leather samples. The wetting ability of the samples is determined by the swelling coefficient equation (Mathew et al., 2006):

$$
\alpha=\left\{A_{S} / W_{0}\right\} \times[1 / d]
$$

where, $A_{s}$ is the weight of solvent absorbed at equilibrium swelling, and $d$ is the density of the solvent used. 
Table II. Recipes for the preparation of all the crust samples ${ }^{b}$

\begin{tabular}{|c|c|c|c|c|c|}
\hline \multirow[b]{2}{*}{ Process } & \multirow[b]{2}{*}{ Ingredients } & \multicolumn{3}{|c|}{ Samples (ingredients in \%) } & \multirow[b]{2}{*}{$\begin{array}{c}\text { Running } \\
\text { time }\end{array}$} \\
\hline & & $\begin{array}{l}\mathrm{BCA}_{0} \mathrm{G}_{0} / \\
\mathrm{NCA}_{0} \mathrm{G}_{0}\end{array}$ & $\begin{array}{l}\mathrm{BCA}_{10} \mathrm{G}_{0} / \\
\mathrm{NCA}_{10} \mathrm{G}_{0}\end{array}$ & $\begin{array}{l}\mathrm{BCA}_{0} \mathrm{G}_{10} / \\
\mathrm{NCA}_{0} \mathrm{G}_{10}\end{array}$ & \\
\hline \multirow[t]{3}{*}{ Soak back } & Water & 200 & 200 & 200 & \\
\hline & Non-ionic detergent & 0.5 & 0.5 & 0.5 & \\
\hline & Oxalic acid & 1 & 1 & 1 & $30^{\prime}$ \\
\hline \multirow[t]{12}{*}{ Rechroming } & Water & 100 & 100 & 100 & \\
\hline & Acid Black dye & 1 & 1 & 1 & $10^{\prime}$ \\
\hline & Formic acid & 1 & 1 & 1 & $20^{\prime}$ \\
\hline & Glutaraldehyde & 3 & 3 & 3 & $20^{\prime}$ \\
\hline & Basic chromium sulfate & 4 & 4 & 4 & \\
\hline & Chrome syntan & 3 & 3 & 3 & \\
\hline & Non-ionic detergent & 0.1 & 0.1 & 0.1 & $30^{\prime}$ \\
\hline & Sulphited fish oil & 1 & 1 & 1 & $15^{\prime}$ \\
\hline & Phenolic syntan & 1 & 1 & 1 & \\
\hline & Melamine syntan & 1 & 1 & 1 & $20^{\prime}$ \\
\hline & Sodium formate & 1 & 1 & 1 & $10^{\prime}$ \\
\hline & Polymeric syntan & 3 & 3 & 3 & $2 \times 10^{\prime}+30^{\prime}$ \\
\hline \multirow[t]{3}{*}{ Neutralization } & Water & 200 & 200 & 200 & \\
\hline & Sodium formate & 1 & 1 & 1 & \\
\hline & Neutralizing syntan & 3 & 3 & 3 & $60^{\prime}$ \\
\hline \multirow[t]{18}{*}{$\begin{array}{l}\text { Retanning/ Dyeing/ } \\
\text { fatliquoring }\end{array}$} & Water & 60 & 60 & 60 & \\
\hline & Acrylic syntan & 4 & 4 & 4 & $20^{\prime}$ \\
\hline & Sulfonated aliphatic oil & 2 & 2 & 2 & $20^{\prime}$ \\
\hline & Dicyna diamide syntan & 3 & 3 & 3 & \\
\hline & Melamine syntan & 3 & 3 & 3 & \\
\hline & GS powder & 6 & 6 & 6 & \\
\hline & Acid Black dye & 3 & 3 & 3 & $60^{\prime}$ \\
\hline & Styrene maleic anhydride c & lymer 2 & 2 & 2 & $20^{\prime}$ \\
\hline & Water & 100 & 100 & 100 & \\
\hline & Anionic water repellent & 1.5 & 1.5 & 1.5 & \\
\hline & Synthetic sperm substitute & 3 & 3 & 3 & \\
\hline & Sulfonated aliphatic oil & 1 & 1 & 1 & \\
\hline & Phospholipid based Semi-s & etic oil 0.5 & 0.5 & 0.5 & \\
\hline & Polymeric syntan & 1 & 1 & 1 & \\
\hline & Preservative & 0.3 & 0.3 & 0.3 & \\
\hline & Non-ionic detergent & 0.2 & 0.2 & 0.2 & $40^{\prime}$ \\
\hline & Acrylic syntan & 2 & 2 & 2 & $30^{\prime}$ \\
\hline & Formic acid & 3 & 3 & 3 & $3 \times 10^{\prime}+30^{\prime}$ \\
\hline \multirow{4}{*}{ Top dyeing } & Water & 100 & 100 & 100 & \\
\hline & Cationic Black dye & 0.5 & 0.5 & 0.5 & $15^{\prime}$ \\
\hline & Formic acid & 1 & 1 & 1 & $20^{\prime}$ \\
\hline & Chrome syntan & 2 & 2 & 2 & $45^{\prime}$ \\
\hline \multirow[t]{3}{*}{ Syntan treatment } & Water & - & 200 & 200 & \\
\hline & Relugan RE & - & 10 & - & $60^{\prime}$ \\
\hline & Relugan GT-50 & - & - & 10 & $60^{\prime}$ \\
\hline
\end{tabular}

\footnotetext{
${ }^{\mathrm{b}} \mathrm{C}=$ Crust leather
} 


\section{Swelling index}

Equilibrium swelling or swelling index of leather samples is measured by the following equation (Mathew et al., 2006):

Swelling index $(\%)=\frac{W_{f}-W_{0}}{W_{0}} \times 100$

\section{Swelling-Deswelling kinetics}

During both swelling and deswelling, weight of the sample was measured as a function of time for determining the degree of swelling, $D o S$ and degree of deswelling, DoD. $D o S$ can be expressed by the following equation (Sivanantham and Tata, 2012):

$D o S=\frac{W_{t s}-W_{0}}{W_{0}}$

where, $W_{t s}$ is the weight of sample at time $t$ in solvent. Similarly, expression of $D o D$ can be the following (Sivanantham and Tata, 2012):

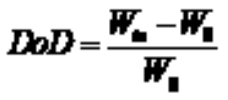

where, $W_{t a}$ is the weight of sample at time $t$ in air.
Fig. 1 depicts the variation of $D o S$ with time which shows the power law behavior. Therefore, the experimental plot is fitted with Voigt-based equation:

$S_{t}=S_{e}\left(1-e^{-t / \tau}\right)$

where, $S_{t}(\mathrm{~g} / \mathrm{g})$ is swelling at time $t, S_{e}$ is equilibrium swelling, $t$ is time (min) for swelling $S_{t}$, and $\tau$ (min) stands for the "rate parameter".

In addition, the swelling time constant $\left(\tau_{s}\right)$ is estimated by fitting the swelling plot (Fig. 2) to the following expression based on Li-Tanaka theory (Sivanantham and Tata, 2012):

$D o S=D o S_{\max }-A_{s} \exp \left(-t / \tau_{s}\right)$

where, $D o S_{\text {max }}$ is the maximum degree of swelling, $A_{s}$ is the amplitude of swelling.

Similarly, using the expression based on Li-Tanaka theory, the deswelling time constant $\left(\tau_{d}\right)$ is estimated by fitting the deswelling plots (Fig. 3) of individual samples to the following equation:

$D o D=D o D_{\max }-A_{d} \exp \left(-t / \tau_{d}\right)$

where, $D o D_{\max }$ is the maximum degree of deswelling, $A_{d}$ is the amplitude of deswelling.

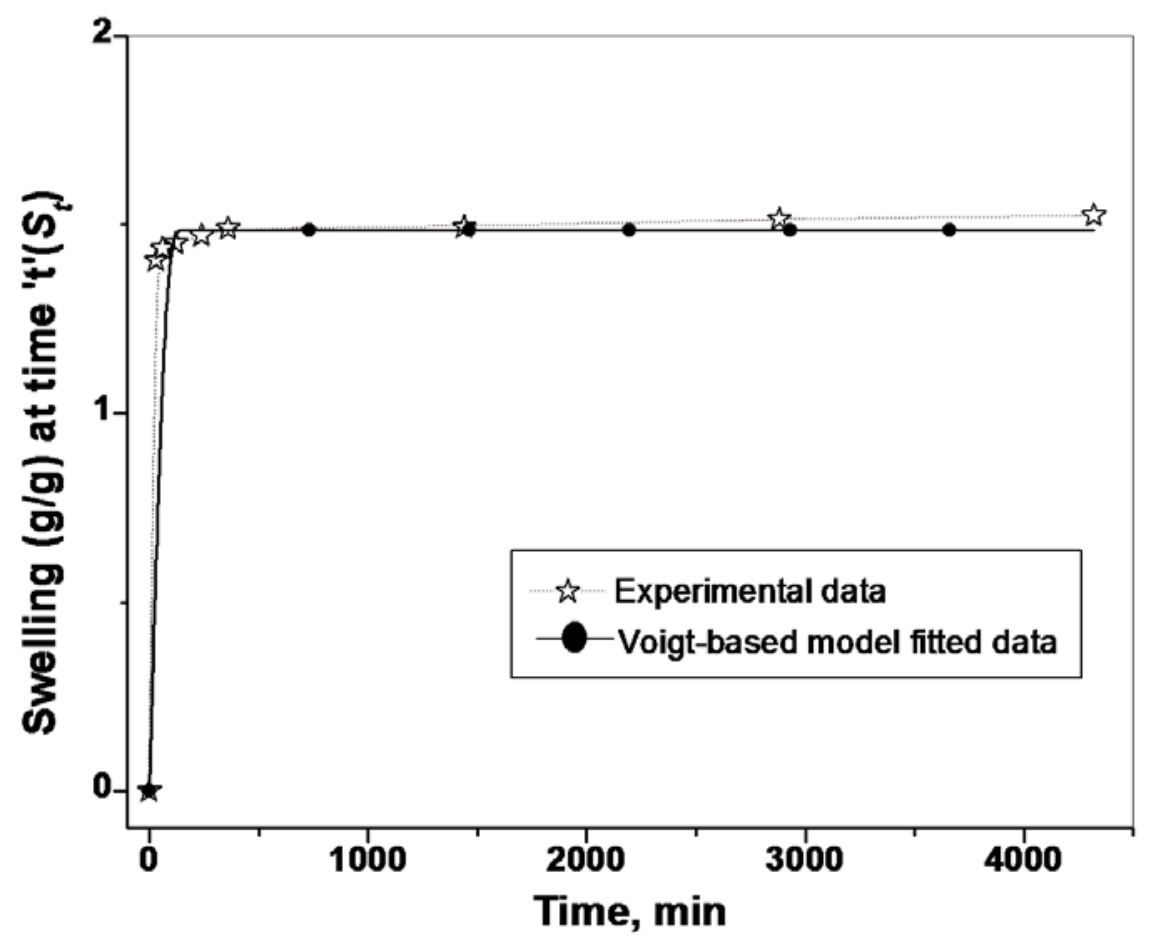

Fig. 1. Representative illustration regarding fitment of Voigt based equation to an experimental plot of swelling kinetics 


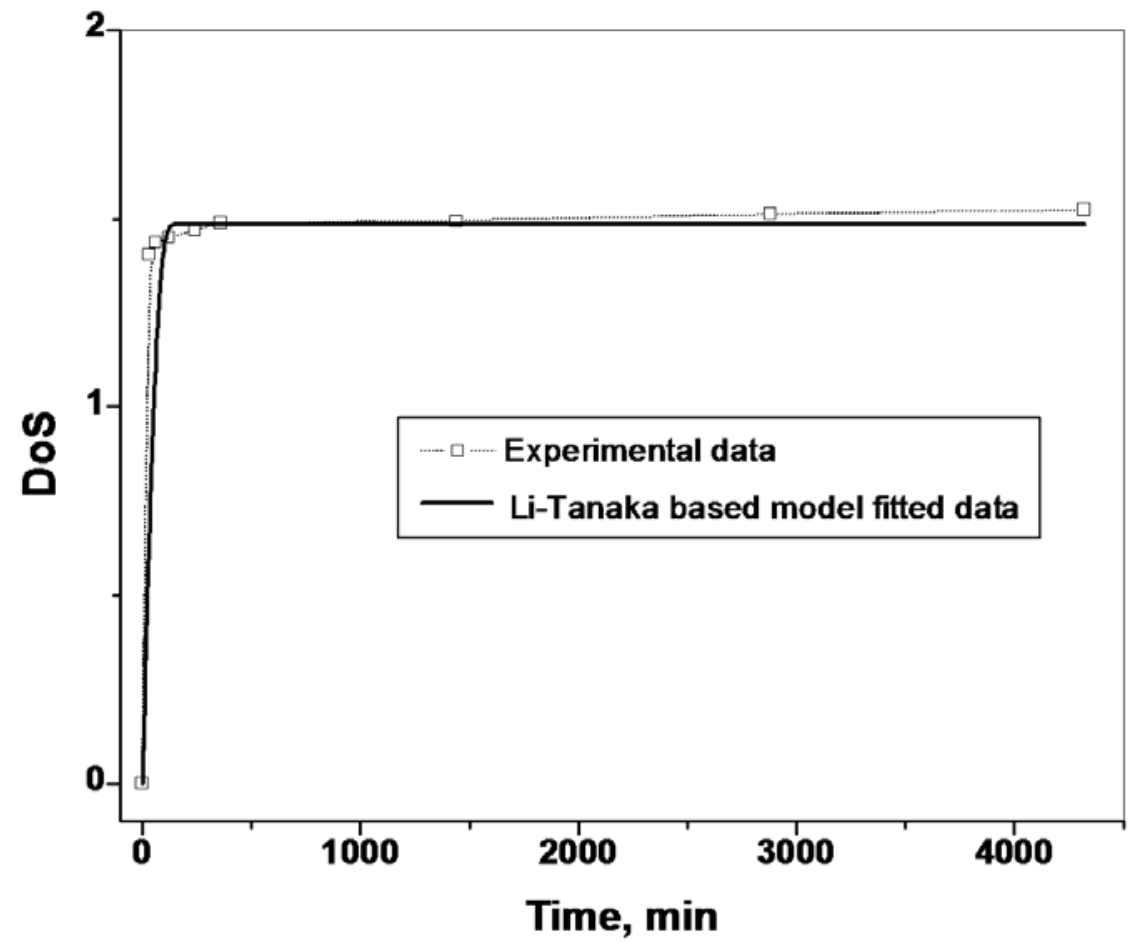

Fig 2. Representative illustration regarding fitment of Li-Tanaka based equation to an experimental plot of swelling kinetics

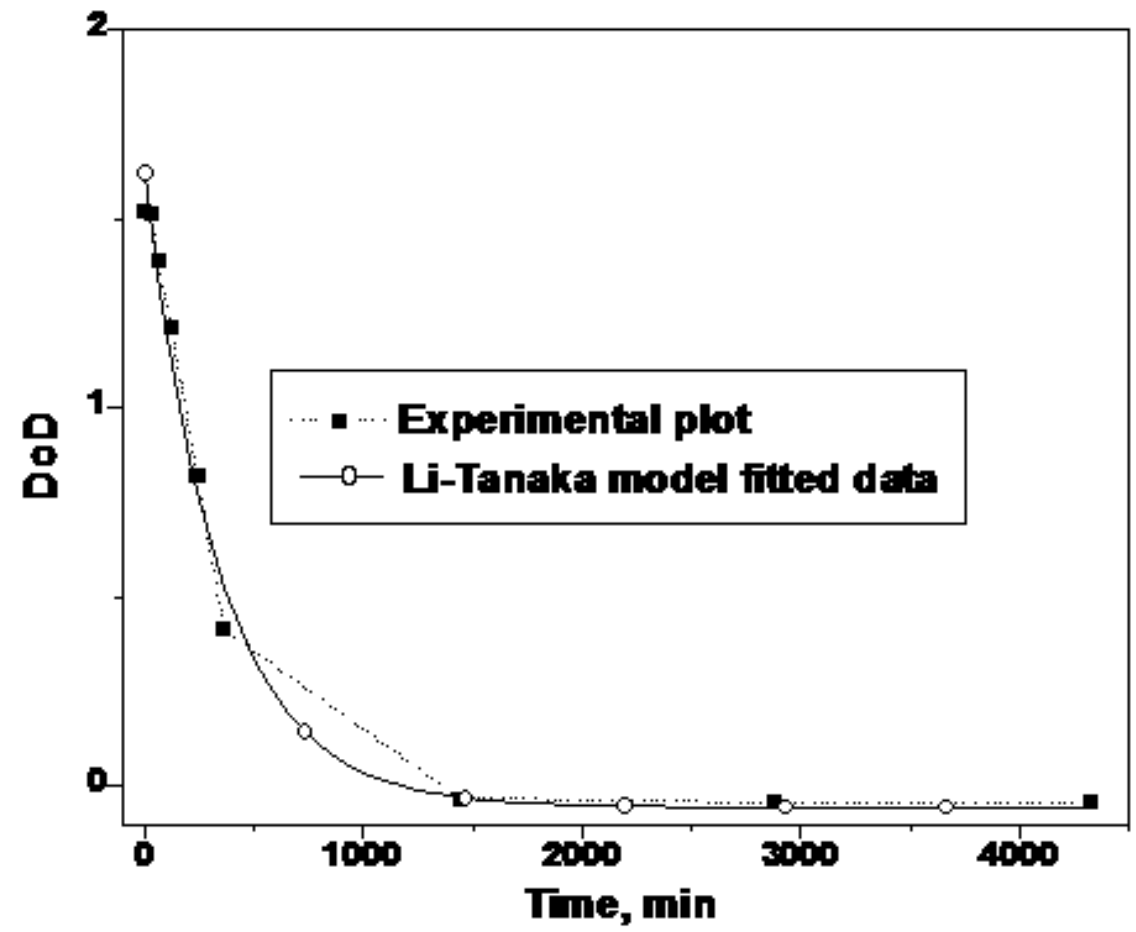

Fig. 3. Representative illustration regarding fitment of Li-Tanaka based equation to an experimental plot of deswelling kinetics 
Table III. Solid contents of the end bath for various samples

\begin{tabular}{lcc}
\hline & \multicolumn{2}{c}{ Solid content of end bath (\%) } \\
\cline { 2 - 3 } Sample Name & $\begin{array}{c}\text { after RE / GT-50 } \\
\text { treatment }\end{array}$ & $\begin{array}{c}\text { after 72 h } \\
\text { swelling }\end{array}$ \\
\hline $\mathrm{BCA}_{0} \mathrm{G}_{0}$ & - & 0.2005 \\
$\mathrm{NCA}_{0} \mathrm{G}_{0}$ & - & 0.1783 \\
$\mathrm{NRA}_{0} \mathrm{G}_{0}$ & - & 0.1884 \\
$\mathrm{BRA}_{0} \mathrm{G}_{0}$ & - & 0.1485 \\
$\mathrm{BCA}_{10} \mathrm{G}_{0}$ & 3.8335 & 0.2173 \\
$\mathrm{NCA}_{10} \mathrm{G}_{0}$ & 3.8799 & 0.2096 \\
$\mathrm{NRA}_{10} \mathrm{G}_{0}$ & 2.9029 & 0.1895 \\
$\mathrm{BRA}_{10} \mathrm{G}_{0}$ & 2.8853 & 0.1679 \\
$\mathrm{BCA}_{0} \mathrm{G}_{10}$ & 4.4089 & 0.2174 \\
$\mathrm{NCA}_{0} \mathrm{G}_{10}$ & 2.6949 & 0.2179 \\
$\mathrm{NRA}_{0} \mathrm{G}_{10}$ & 2.81 & 0.1988 \\
$\mathrm{BRA}_{0} \mathrm{G}_{10}$ & 3.2187 & 0.2089 \\
\hline
\end{tabular}
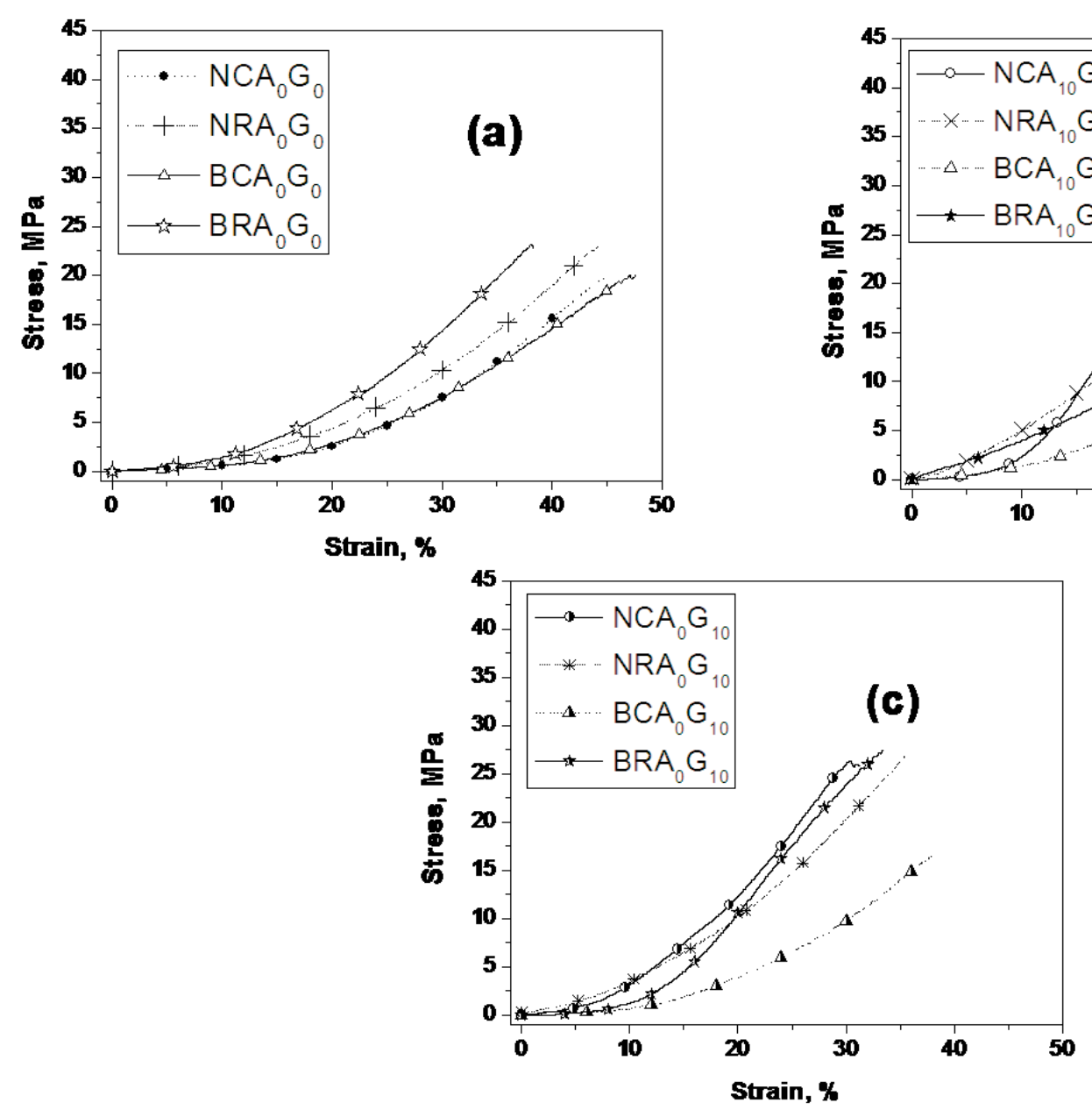

\section{Results and discussion}

\section{Mechanical properties}

In general, it can be observed that the tensile properties (e.g. tensile modulus, tensile strength) of untreated samples (Fig. 4a) are improved by treatment with either Relugan RE (Fig. 4b) or Relugan GT-50 (Fig. 4c). Stress-strain plots clearly show that the Relugan RE treated samples tolerate higher level of stresses than both the GT-50 treated and untreated leathers at all the strain levels. Table IV shows that tensile strength, modulus, and crosslink densities of Relugan RE treated and GT-50 treated leathers are superior as compared to the respective untreated samples (i.e. $\mathrm{NCA}_{0} \mathrm{G}_{0}, \mathrm{NRA}_{0} \mathrm{G}_{0}$, $\mathrm{BCA}_{0} \mathrm{G}_{0}, \mathrm{BRA}_{0} \mathrm{G}_{0}$ ). On the contrary, elongation-at-break values of the treated samples are reduced as compared to those of the untreated samples (Table IV). This can be possible as both acrylic and glutaraldehyde molecules may form

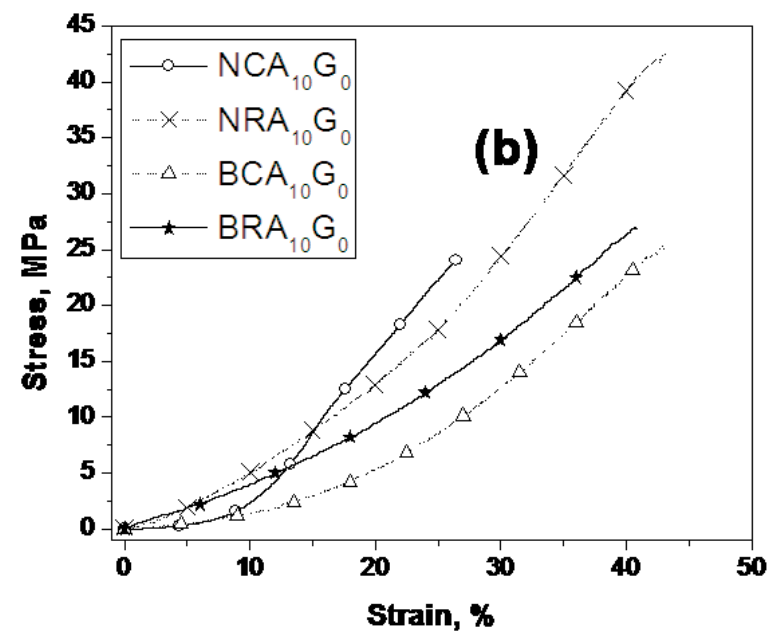


crosslinking points of higher functionality inside collagen matrix. Theoretically, networks containing tetra-functional crosslinking points should have a lower elongation-at-break than networks containing tri-functional crosslinks (Nielsen and Landel,1994). It is to be noted that among the untreated samples, rechromed samples ((i.e. $\mathrm{NRA}_{0} \mathrm{G}_{0}$ and $\mathrm{BRA}_{0} \mathrm{G}_{0}$ ) produce better tensile properties in comparison to the corresponding crust samples (i.e. $\mathrm{NCA}_{0} \mathrm{G}_{0}$ and $\mathrm{BCA}_{0} \mathrm{G}_{0}$ ). This can be possible as average thicknesses and hence the crosssectional areas of the crust samples are greater as compared to the respective rechromed samples. It may give rise to lesser compactness of the crust samples in comparison to rechromed samples (Table IV). Such enhancement in thickness for crust samples might be due to excessive swelling during the post-neutralization stages. Reduction in compactness for crusts is also reflected in the lowering of crosslink densities for untreated crust samples as compared to the untreated rechromed samples (Table IV). In this regard, remarkably better elongation-at-break for $\mathrm{BCA}_{0} \mathrm{G}_{0}$ as compared to $\mathrm{BRA}_{0} \mathrm{G}_{0}$ indicates presence of higher extent of void spaces in $\mathrm{BCA}_{0} \mathrm{G}_{0}$. Such higher extent of void spaces in $\mathrm{BCA}_{0} \mathrm{G}_{0}$ ensure easier orientation of macromolecules in the direction of applied tensile force as inter-chain distances are widened owing to excess swelling during post-neutralization stage. Indeed, $\mathrm{NRA}_{0} \mathrm{G}_{0}$ shows the highest crosslink density as well as tensile strength among all the samples. It can be possible since the $-\mathrm{COO}^{-}$of Relugan $\mathrm{RE}$ can be co-ordinated with the $\mathrm{Cr}^{3+}$ of the Cr-complex during the rechroming stage. On the contrary, crust samples are comparatively crowded with different types of molecules unlike the rechromed sample. Moreover, in case of rechromed samples, the change of elongation-at-break owing to RE treatment is less pronounced than that happened owing to GT-50 treatment (Table IV). In this regard, Madhan et al. (2002) reported that the treatment of collagen fibre with acrylic polymer like polymethacrylic acid is likely to open up the collagen molecule through electrostatic forces as they contain active sites for charge interactions. As acrylic syntans possess the ability to open up the collagen molecule through electrostatic forces, these can minimize the interchain interactions preferably in the direction perpendicular to the backbone. This in turn can increase the mobility of collagen macromolecules towards the applied force giving rise to higher elongation-at-break as compared to GT-50 treated samples.

\section{Swelling}

As leather is basically a fibrous collagen material, swelling characteristics of leather depends on various factors such as, a) hydrophobicity/ hydrophilicity of the sample, b) crosslink density, c) nature and stability of crosslinks, d) $\mathrm{pH}$, e) temperature, f) extent of void spaces within the network, g) fibre-filler interactions etc. Swelling of collagen and other fibrous proteins, basic components of leather, in a solvent or solution is governed by the Donnan membrane effect, and by the cohesion of the protein (Bowes and Kenten, 1950). Moreover, hydrodynamic swelling of leather in a solvent is closely related to the wettability of leather towards that particular solvent. In fact, the process of leather wetting in water constitutes of four general steps: a) water spreads

\section{Table IV. Tensile properties of various samples}

\begin{tabular}{|c|c|c|c|c|c|c|c|c|}
\hline \multirow{2}{*}{$\begin{array}{l}\text { Sample } \\
\text { name }\end{array}$} & \multirow{2}{*}{$\begin{array}{c}\text { Avg. } \\
\text { Thickness, } \\
\text { mm }\end{array}$} & \multirow{2}{*}{$C_{1}$} & \multirow{2}{*}{$\begin{array}{c}N_{C}= \\
2 C_{I} / R T, \\
\text { mol.m }{ }^{-3}\end{array}$} & \multirow{2}{*}{$\begin{array}{c}\text { Tensile } \\
\text { strength, } \\
\mathrm{MPa}\end{array}$} & \multirow{2}{*}{$\begin{array}{l}\text { Elongation- } \\
\text { at- break } \\
(\%)\end{array}$} & \multicolumn{3}{|c|}{ Stress at different strain $\%$} \\
\hline & & & & & & $10 \%$ & $20 \%$ & $30 \%$ \\
\hline $\mathrm{NCA}_{0} \mathrm{G}_{0}$ & 1.482 & 0.90 & 725.86 & 19.76 & 44.70 & 0.55 & 2.58 & 7.51 \\
\hline $\mathrm{NRA}_{0} \mathrm{G}_{0}$ & 1.262 & 1.85 & 1491.51 & 23.56 & 45.00 & 1.16 & 4.38 & 10.30 \\
\hline $\mathrm{BCA}_{0} \mathrm{G}_{0}$ & 1.956 & 0.96 & 773.24 & 19.98 & 47.60 & 0.57 & 2.81 & 7.51 \\
\hline $\mathrm{BRA}_{0} \mathrm{G}_{0}$ & 1.350 & 2.28 & 1842.19 & 23.14 & 38.12 & 1.42 & 6.29 & 14.31 \\
\hline $\mathrm{NCA}_{10} \mathrm{G}_{0}$ & 1.642 & 3.71 & 2993.04 & 24.07 & 26.48 & 2.36 & 15.67 & - \\
\hline $\mathrm{NRA}_{10} \mathrm{G}_{0}$ & 1.292 & 8.30 & 6703.22 & 42.50 & 43.10 & 5.11 & 12.89 & 24.39 \\
\hline $\mathrm{BCA}_{10} \mathrm{G}_{0}$ & 1.810 & 2.25 & 1813.46 & 25.30 & 42.90 & 1.39 & 5.26 & 12.63 \\
\hline $\mathrm{BRA}_{10} \mathrm{G}_{0}$ & 1.618 & 6.50 & 5243.56 & 27.00 & 40.70 & 4.00 & 9.49 & 16.87 \\
\hline $\mathrm{NCA}_{0} \mathrm{G}_{10}$ & 1.626 & 5.02 & 4048.08 & 26.00 & 31.08 & 3.20 & 12.25 & 26.00 \\
\hline $\mathrm{NRA}_{0} \mathrm{G}_{10}$ & 1.320 & 5.65 & 4563.83 & 27.27 & 35.92 & 3.48 & 10.16 & 20.24 \\
\hline $\mathrm{BCA}_{0} \mathrm{G}_{10}$ & 1.934 & 1.36 & 1097.16 & 20.47 & 43.50 & 0.69 & 3.89 & 9.77 \\
\hline $\mathrm{BRA}_{0} \mathrm{G}_{10}$ & 1.630 & 5.21 & 4206.64 & 27.50 & 33.40 & 1.20 & 10.60 & 24.04 \\
\hline
\end{tabular}


over and wets the leather surface; b) water penetrates into the leather; c) water wets the fibre network; d) the leather rehydated by water due to the attractive interaction between water and leather (Herrmann, 2006).

Among the untreated samples, butt samples (i.e. $\mathrm{BRA}_{0} \mathrm{G}_{0}$ and $\mathrm{BCA}_{0} \mathrm{G}_{0}$ ) show higher $S_{\mathrm{e}}$ values as compared to those of the neck samples (Table V). The comparatively higher quantity of water retention at equilibrium in the butt area can be ascribed to less compact fibre structures in the butt area owing to higher angle of weave. In fact, fibres weaving, fibre bundles splitting, separation and coalescence can influence the wetting and swelling characteristics of leather (Jankauskaite et al., 2012). The lower $S_{\mathrm{e}}$ values for neck area based sample indicate intense cohesive forces among fibre and fibre bundles owing to lower angle of weave in the neck region. Moreover, it has been observed that rechromed samples envisages higher $S_{e}$ values than the corresponding crust samples (i.e. $\mathrm{BRA}_{0} \mathrm{G}_{0}>\mathrm{BCA}_{0} \mathrm{G}_{0}$ and $\mathrm{NRA}_{0} \mathrm{G}_{0}>\mathrm{NCA}_{0} \mathrm{G}_{0}$ ). Higher swelling in the equilibrium for rechromed samples can be attributed to better hydrophilicity of the samples as compared to crust samples as crust samples are loaded with varieties of hydrophobic ingredients (e.g. anionic water repelling agent, sulfonated aliphatic oil, synthetic sperm substitute, phospholipid based semi-synthetic oil) which are completely absent in the rechromed samples (Table I and Table II). Moreover, greater water holding capacity of rechromed samples may indicate availability of higher extent of void spaces as the filling materials (reinforcing / non-reinforcing) and retanning agents such as, vegetable tannins, styrene-maleic anhydride copolymer, dicyandiamide syntans are absent in these samples (Table I).
Moreover, hydrophobic ingredients like melamines are present at lesser quantity inside the rechromed samples (Table I). Hence, availability of greater void spaces and higher hydrophilicity may ensure higher retention of water molecules inside the rechromed samples as compared to the crust samples.

The swelling time constants $\left(\tau_{s}\right)$ of treated and untreated samples have been evaluated via fitment of both Voigt-based equation (equation 8) and Li-Tanaka equation (equation 9) on the experimental swelling plot (Fig. 1 and 2). It is to be noted that the order of $\tau_{\mathrm{s}}$ values for the untreated samples (i.e. $\mathrm{NRA}_{0} \mathrm{G}_{0}>\mathrm{BRA}_{0} \mathrm{G}_{0}>\mathrm{NCA}_{0} \mathrm{G}_{0}>\mathrm{BCA}_{0} \mathrm{G}_{0}$ ) is slightly different than the order for $\mathrm{Se}$ values of the samples (Table V). Samples from neck area shows higher $S_{s}$ values (Table V and Table VI) and accordingly lower swelling rate (equation 8 and 9) owing to greater compactness as a result of lower angle of weave. Interestingly, lower swelling rate is observed in case of rechromed samples despite better hydrophilic character and availability of greater void spaces in rechromed samples. Here, the higher crosslink densities in the rechromed samples (Table IV) can be responsible behind such lower swelling rate for the rechromed samples (Table V and Table VI).

In all the RE treated samples, higher $\tau_{s}$ values are obtained in comparison to respective untreated samples (Table $\mathrm{V}$ and Table VI), which implies lesser degree of swelling (equation 9) as a result of increased crosslinking densities for all RE treated samples with respect to untreated ones (Table IV). In general, RE treatment reduces $S_{e}$ values except $\mathrm{NCA}_{10} \mathrm{G}_{0}$ where the water retention at equilibrium is noted to be

Table V. Data corresponding to Fitment by Voigt-based equation on swelling plot [11]

\begin{tabular}{|c|c|c|c|c|c|c|}
\hline Sample & $\mathrm{Chi}^{2} / \mathrm{DoF}$ & $R^{2}$ & $S_{e}$ & Error $(\%)$ & $\tau_{s}, \min$ & Error (\%) \\
\hline$\overline{\mathrm{BCA}_{0} \mathrm{G}_{0}}$ & 0.0003 & 0.99701 & 1.48372 & 0.745424 & 10.44496 & 12.88907 \\
\hline $\mathrm{BRA}_{0} \mathrm{G}_{0}$ & 0.0011 & 0.99652 & 1.58479 & 0.804523 & 10.64963 & 13.40788 \\
\hline $\mathrm{NCA}_{0} \mathrm{G}_{0}$ & 0.0015 & 0.9939 & 1.2741 & 1.06585 & 10.5363 & 18.12243 \\
\hline $\mathrm{NRA}_{0} \mathrm{G}_{0}$ & 0.0033 & 0.98571 & 1.29292 & 1.64434 & 11.8022 & 22.87265 \\
\hline $\mathrm{BCA}_{10} \mathrm{G}_{0}$ & 0.00305 & 0.98057 & 1.11191 & 1.929113 & 12.83368 & 23.57546 \\
\hline $\mathrm{BRA}_{10} \mathrm{G}_{0}$ & 0.00353 & 0.98279 & 1.26996 & 1.804781 & 11.40251 & 26.60205 \\
\hline $\mathrm{NCA}_{10} \mathrm{G}_{0}$ & 0.00091 & 0.99631 & 1.40166 & 0.828304 & 10.84011 & 13.35501 \\
\hline $\mathrm{NRA}_{10} \mathrm{G}_{0}$ & 0.00342 & 0.98257 & 1.2437 & 1.823591 & 12.48751 & 23.2018 \\
\hline $\mathrm{BCA}_{0} \mathrm{G}_{10}$ & 0.00106 & 0.99577 & 1.41106 & 0.884441 & 9.725734 & 17.69111 \\
\hline $\mathrm{BRA}_{0} \mathrm{G}_{10}$ & 0.00385 & 0.98535 & 1.4405 & 1.669559 & 12.60557 & 20.95046 \\
\hline $\mathrm{NCA}_{0} \mathrm{G}_{10}$ & 0.00067 & 0.99743 & 1.43365 & 0.687058 & 8.716116 & 17.69372 \\
\hline $\mathrm{NRA}_{0} \mathrm{G}_{10}$ & 0.00186 & 0.99159 & 1.3266 & 1.266395 & 13.74948 & 14.06572 \\
\hline
\end{tabular}


enhanced. It is also observed that the solid content of the end bath, generated during processing of $\mathrm{NCA}_{10} \mathrm{G}_{0}$, is the highest (Table III). Such solid content (3.8799\%) can be owing to the following: a) considerable extent of RE molecules may unable to penetrate into the hide matrix from the bath, $b$ ) ingredients already present prior to swelling may transfer from matrix to the bath. During RE treatment, the penetration of RE molecule inside $\mathrm{NCA}_{0} \mathrm{G}_{0}$ might be hampered as the bigger RE molecules may experience higher restrictions owing to compact nature of the neck region of the crust.

Among the GT-50 treated samples, the $\tau_{s}$ values for rechromed samples are in the higher side in comparison to crust samples (Table V). It indicates the possibility of higher number of stable crosslink formation as a result of easier availability of free $-\mathrm{NH}_{2}$ groups (both $\varepsilon$-amino and $\alpha$ amino) of collagen in rechromed samples. These free $-\mathrm{NH}_{2}$ groups can interact with $-\mathrm{CHO}$ groups of GT-50 through nucleophilic substitution via formation of carbon-nitrogen double bond (Morrison and Boyd, 1987). Moreover, GT-50 may also interact with other less reactive unoccupied functional groups, like, guanidinyl, secondary amino and hydroxyl groups (Migneault et al., 2004). On the contrary, for the GT-50 treated crust samples, $\tau_{s}$ are reduced as compared to untreated samples despite increase in cross-linking densities (Table IV). This may be possible owing to formation of physical crosslinks in larger proportion in comparison to generation of chemical crosslinks. Moreover, crosslink density may have improved in the direction along the backbone, whereas in the perpendicular direction of backbone the crosslink density may not be increased that much.

\section{Deswelling}

Deswelling is the reverse process of swelling, which is related to change of a macromolecule from a relaxed rubbery state to a glassy or more preferably to a partially rubbery state as leathery state lies in between glassy and rubbery state (Ganji et al., 2010). The deswelling time constants $\left(\tau_{d}\right)$ of treated and untreated samples have been evaluated via fitment of Li-Tanaka equation on the experimental deswelling plot (Fig. 3). Deswelling time constants $\left(\tau_{d}\right)$ are found in the following order: $\mathrm{BCA}_{0} \mathrm{G}_{0}>\mathrm{NCA}_{0} \mathrm{G}_{0}>\mathrm{BRA}_{0} \mathrm{G}_{0}>\mathrm{NRA}_{0} \mathrm{G}_{0}$ (Table VII). This order is completely reverse to the order obtained for $\tau_{s}$ (Table VI). During deswelling, the transition from relaxed rubbery state to partially rubbery state would be faster if the relaxed flexible chains become rigid and strained easily. The $\tau_{d}$ values for almost all the RE treated samples have been increased in comparison to the untreated samples except the butt crust sample (Table VII). This can be possible as the treatment by acrylic syntans can already increase the rigidity of the macromolecular chains irreversibly through formation of stable crosslinks via coordinate linkage between $\mathrm{Cr}^{3+}$ and $-\mathrm{COO}^{-}$group of $\mathrm{RE}$ chains (Jankauskaite et al., 2012). Such improvement of crosslink density in RE treated samples as compared to untreated samples has already been recorded earlier (Table IV). For the butt crust samples, RE treatment has resulted in degradation of $\tau_{d}$ values as the crosslink density for $\mathrm{BCA}_{10} \mathrm{G}_{0}$ is not substantially higher with respect the untreated sample (Table IV). Hence, swelled $\mathrm{BCA}_{10} \mathrm{G}_{0}$ might be more relaxed, and hence deswelling would be faster (Table VI). On the contrary, for GT-50 treated samples, $\tau_{d}$ values for almost all samples have been slightly elevated as the swelled GT-50

Table VI. Data corresponding to Fitment by Li-Tanaka based equation on the swelling plot

\begin{tabular}{lrrrrrrrr}
\hline Sample & $\mathrm{Chi}^{2} / \mathrm{DoF}$ & $R^{2}$ & DoS $_{\max }$ & Error & $A_{d}$ & Error & $\tau_{s}$, min & Error \\
\hline $\mathrm{BCA}_{0} \mathrm{G}_{0}$ & 0.00097 & 0.99701 & 1.48372 & 0.01194 & -1.48358 & 0.0333 & 10.44562 & 1.44571 \\
$\mathrm{BRA}_{0} \mathrm{G}_{0}$ & 0.00128 & 0.99652 & 1.58479 & 0.01377 & -1.5846 & 0.03837 & 10.65013 & 1.53398 \\
$\mathrm{NCA}_{0} \mathrm{G}_{0}$ & 0.00146 & 0.9939 & 1.2741 & 0.01467 & -1.27391 & 0.04088 & 10.53646 & 2.05104 \\
$\mathrm{NRA}_{0} \mathrm{G}_{0}$ & 0.00353 & 0.98571 & 1.29293 & 0.02297 & -1.29255 & 0.06369 & 11.80425 & 2.90626 \\
$\mathrm{BCA}_{10} \mathrm{G}_{0}$ & 0.00356 & 0.98057 & 1.11191 & 0.02317 & -1.11127 & 0.06395 & 12.83799 & 3.26304 \\
$\mathrm{BRA}_{10} \mathrm{G}_{0}$ & 0.00412 & 0.98279 & 1.26996 & 0.02476 & -1.26965 & 0.06878 & 11.40337 & 3.2627 \\
$\mathrm{NCA}_{10} \mathrm{G}_{0}$ & 0.00106 & 0.99631 & 1.40166 & 0.01254 & -1.40149 & 0.03491 & 10.84052 & 1.55566 \\
$\mathrm{NRA}_{10} \mathrm{G}_{0}$ & 0.00399 & 0.98257 & 1.24364 & 0.0245 & -1.24304 & 0.06772 & 12.4941 & 3.12304 \\
$\mathrm{BCA}_{0} \mathrm{G}_{10}$ & 0.00262 & 0.99107 & 1.42095 & 0.01809 & -1.37364 & 0.05427 & 9.725734 & 1.8762 \\
$\mathrm{BRA}_{0} \mathrm{G}_{10}$ & 0.0067 & 0.97815 & 1.42237 & 0.03093 & -1.42237 & 0.08748 & 12.60557 & 2.2489 \\
$\mathrm{NCA}_{0} \mathrm{G}_{10}$ & 0.00078 & 0.99743 & 1.43365 & 0.01064 & -1.43362 & 0.02986 & 8.71601 & 1.65201 \\
$\mathrm{NRA}_{0} \mathrm{G}_{10}$ & 0.00217 & 0.99159 & 1.3266 & 0.01815 & -1.32603 & 0.0499 & 13.75248 & 2.08909 \\
\hline
\end{tabular}


Mondal and Chattopadhyay

Table VII. Data corresponding to Fitment by Li-Tanaka based equation on the deswelling plot

\begin{tabular}{lrrrrrrrr}
\hline Sample & $\mathrm{Chi}^{2} / \mathrm{DoF}$ & $R^{2}$ & $\mathrm{DoD}_{\mathrm{ma}}$ & Error & $A_{d}$ & Error & $\tau_{d}$, min & Error \\
\hline $\mathrm{BCA}_{0} \mathrm{G}_{0}$ & 0.00586 & 0.99073 & -0.05561 & 0.04596 & 1.67821 & 0.06699 & 286.84744 & 38.04581 \\
$\mathrm{BRA}_{0} \mathrm{G}_{0}$ & 0.00635 & 0.98994 & -0.03605 & 0.04573 & 1.71894 & 0.07152 & 221.06234 & 23.50394 \\
$\mathrm{NCA}_{0} \mathrm{G}_{0}$ & 0.00506 & 0.98914 & -0.06006 & 0.04132 & 1.46242 & 0.06327 & 257.14262 & 28.788 \\
$\mathrm{NRA}_{0} \mathrm{G}_{0}$ & 0.00601 & 0.98732 & -0.04903 & 0.04405 & 1.49823 & 0.07012 & 195.68858 & 23.37947 \\
$\mathrm{BCA}_{0} \mathrm{G}_{10}$ & 0.0069 & 0.98342 & -0.07802 & 0.04846 & 1.37529 & 0.07374 & 268.31856 & 37.4637 \\
$\mathrm{BRA}_{10} \mathrm{G}_{0}$ & 0.0104 & 0.98075 & -0.06638 & 0.05926 & 1.56797 & 0.0907 & 257.94179 & 38.6281 \\
$\mathrm{NCA}_{10} \mathrm{G}_{0}$ & 0.00831 & 0.98588 & -0.08453 & 0.0535 & 1.63188 & 0.08064 & 285.6041 & 37.18158 \\
$\mathrm{NRA}_{10} \mathrm{G}_{0}$ & 0.00974 & 0.98016 & -0.05833 & 0.05713 & 1.49838 & 0.08802 & 246.24461 & 37.2393 \\
$\mathrm{BCA}_{0} \mathrm{G}_{10}$ & 0.00984 & 0.98383 & -0.08657 & 0.05742 & 1.67217 & 0.08851 & 245.56154 & 33.45288 \\
$\mathrm{BRA}_{0} \mathrm{G}_{10}$ & 0.01741 & 0.97462 & -0.09059 & 0.07586 & 1.77483 & 0.11822 & 226.93128 & 38.67164 \\
$\mathrm{NCA}_{0} \mathrm{G}_{10}$ & 0.00923 & 0.98517 & -0.08588 & 0.056 & 1.68497 & 0.08535 & 265.69354 & 34.99125 \\
$\mathrm{NRA}_{0} \mathrm{G}_{10}$ & 0.01189 & 0.97776 & -0.09155 & 0.06119 & 1.59522 & 0.09949 & 192.49189 & 27.56937 \\
\hline
\end{tabular}

treated samples would be relaxed since glutaraldehyde reacts reversibly with amino groups of proteins over a wide $\mathrm{pH}$ range ( $\geq \mathrm{pH} 3.0$ ), except between $\mathrm{pH} 7.0$ to 9.0 where only a little reversibility is observed (Migneault et al., 2004).

Table VII shows that the untreated samples possess the lowest $D o D_{\max }$ values, and the GT-50 treated samples show the highest DoDmax values. The $D o D_{\max }$ values for the RE treated samples lay in between the untreated and GT-50 treated samples. Moreover, crust samples depict the higher $D o D_{\max }$ values than those of rechromed samples. In this regard, $D o D_{\max }$ values can be directly related to the solid contents $(\%)$ of the end baths after swelling (Table III). Higher solid content of end bath after swelling indicates higher material loss, and such material loss should be higher for crust samples as crust samples are populated with different types of molecules reversibly attached within the leather matrix. Higher solid content (\%) of the end baths after swelling for both RE and GT-50 treated samples may be ascribed to the following:

a) $-\mathrm{COO}^{-}$group of $\mathrm{RE}$ can be involved competitively in the salt link formation with $-\mathrm{NH}_{3}{ }^{+}$group of protein which is already interacted with $-\mathrm{SO}_{3}{ }^{-}$group of acid dye as well as of aliphatic oil used as lubricating agent. Thus, $-\mathrm{COO}^{-}$ group can make free a portion of the bound acid dye or sulphonated aliphatic oil which can move to water from the leather matrix during swelling.

b) - CHO group of GT-50 can strongly interact with the available $-\mathrm{NH}_{2}$ group of collagen, and thereby can displace some molecules which are already attached to the $-\mathrm{NH}_{2}$ group of collagen by weaker bonding forces.

\section{Conclusion}

(a) Substantial improvement in crosslink densities is achieved for all the leather samples which are reflected in the enhancement both in the mechanical properties as well as in the resistance towards hydrodynamic swelling.

(b) The improvement in these properties is more pronounced in case of leathers treated with crosslinking agents based on acrylic copolymers as compared to gluteraldehyde based tanning agents as gluteraldehyde, if present $\leq 10 \%$, interacts reversibly with the collagen chains at acidic $\mathrm{pH}$.

(c) As a result of one complete cycle of swelling / deswelling, a little quantity of material loss has been incurred in all the samples, and this material loss is the highest in case of glutaraldehyde treated leather followed by RE treated leather.

(d) Such post-treatment of leather can be a useful measure to overcome shortcomings in the mechanical properties of leather samples already manufactured in the industry.

\section{References}

Bowes JH and Kenten RH (1950), The Swelling of collagen in alkaline solutions 1. swelling in solutions of sodium hydroxide, Biochem. 46: 1-8.

Christner J, Pfleiderer E, Taeger T and Wick G (1990), U S Patent Number: 4,961,750 Assignee: Riihm GmbH, Darmstadt, Fed. Rep. of Germany. 
Damink LHHO, Dijkstra PJ, Van LMJA, Van WPB, Nieuwenhuis P and Feijen J (1995), Glutaraldehyde as a crosslinking agent for collagen-based biomaterials, $J$. Mater. Sci.- Mater. Med. 6: 460-472.

Dutta SS (1985), An introduction to the principles of leather manufacture, published by Indian Leather Technologist's Association 1-20.

Ganji F, Samira VF and Ebrahim VF (2010), Theoretical Description of Hydrogel Swelling: A Review, Iran. Polym. J. 19: 375-398.

Heidemann E (1993), Fundamentals of leather manufacturing, published by Roetherdruck, Darmstadt- Eduard Roether $\mathrm{Kg}$.

Herrmann W (2006), Waterproof Leather - Requirements and Technology, Leather International 9: 56-58.

Jankauskaite V, Jiyembetova I, Gulbiniene A, Širvaityte J, Beleška K and Urbelis V (2012), Comparable evaluation of leather waterproofing behaviour upon hide quality. I. Influence of retanning and fatliqouring agents on leather structure and properties, Mater. Sci. 18: 150 - 157.

Jeyapalina S, Attenburrow GE and Covington AD (2007), Dynamic mechanical thermal analysis (DMTA) of leather Part 1: effect of tanning agent on the glass transition temperature of collagen, J. Soc. Leath. Tech. Ch. 91: 236-242.

Madhan B, Muralidharan C and Jayakumar R (2002), Study on the stabilisation of collagen with vegetable tannins in the presence of acrylic polymer, Biomaterials 23: 2841-2847.

Mathew L, Joseph KU and Joseph R (2006), Swelling behaviour of isora/natural rubber composites in oils used in automobiles, Bull. Mater. Sci. 29: 91-99.
Migneault I, Dartiguenave C, Bertrand MJ and Waldron KC (2004), Glutaraldehyde: behavior in aqueous solution, reaction with proteins, and application to enzyme crosslinking, BioTechniques 37: 790- 802.

Morrison RT and Boyd RN (1987), Organic Chemistry, Massachusetts: Allyn and Bacon $4^{\text {th }}$ Ed., p 208.

Nielsen L E and Landel R F (1994), Mechanical Properties of Polymers and Composites $2^{\text {nd }}$ Ed. Boca Raton: CRC press, p 276.

Saleem R, Adnan A and Qureshi FA (2013) Study of Viscosity Behavior and Retanning Properties of Sulfonated Glutaric Dihydrazide Formaldehyde Condensate under Different Reactant Ratios, Russ. J. Appl. Chem. 86: 1798- 1804.

Sivanantham M and Tata BVR (2012), Swelling/deswelling of polyacrylamide gels in aqueous $\mathrm{NaCl}$ solution: Light scattering and macroscopic swelling study, pramana-j. phys. 79: 457-469.

Thanikaivelan P, Rao JR, Nair BU and Ramasami T (2002), Zero Discharge Tanning: A Shift from Chemical to Biocatalytic Leather Processing, Environ. Sci. Technol. 36: 4187- 4194.

Tyagi PK, Chatopadhyay PK and Mukherjee G (2014), Glutaraldehyde Retannage - a Review and Assessment of the Properties, J. Soc. Leath. Tech. Ch. 98: 99-107.

Received: 22 July 2014; Revised: 04 November 2015; Accepted: 31 January 2016. 